\title{
A linguagem gráfica das capas de coleções da Livraria José Olympio Editora no decênio de 1930: uma análise baseada em princípios do design da informação
}

The graphic language of the covers of José Olympio publishing house book series in the 1930s: an analysis based on information design principles

\section{Carla Fernanda Fontana \& Priscila Lena Farias}

palavras-chave: capas de livro, tipografia, letreiramento, memória gráfica

\begin{abstract}
Este artigo analisa a linguagem gráfica das capas de livros publicados em coleções pela Livraria José Olympio Editora no decênio de 1930. Baseado sobretudo em fontes primárias, o estudo examina e descreve os recursos gráficos utilizados no layout das capas como forma de reforçar o pertencimento dos livros a um mesmo conjunto e também aqueles adotados como modo de diferenciar os volumes entre si. O texto relaciona a ampliação e a diversificação do catálogo da editora a alterações no projeto visual dos livros e mostra as tentativas da José Olympio de se adequar aos diversos públicos leitores por meio de diferenciações no projeto visual das publicações. Busca também compreender o papel dos artistas gráficos na elaboração das capas, contribuindo para o campo de pesquisas sobre a memória gráfica brasileira.
\end{abstract}

\section{keywords: book covers, typography, lettering, graphic memory}

This article analyzes the graphic language of book covers within the book series published by Livraria José Olympio publishing house in the 1930s. Based mostly on primary sources, the study examines and describes the graphic features used in the covers layouts as a way to reinforce the belonging of individual volumes to each series and also those that serve as distinctive features between them. The text relates the expansion and diversification of the publishing house catalogue to changes in the visual design of the books and shows José Olympio's attempts to suit different audiences through various layouts. It also seeks to understand the role of graphic artists in the creation of the covers, contributing to the field of research on Brazilian graphic memory.

\section{Introdução}

A Livraria José Olympio iniciou suas atividades em São Paulo em 1931, como uma loja de obras raras. Já no ano seguinte a empresa publicou seu primeiro livro e, ainda no decênio de 1930, se tornou uma das principais editoras do mercado brasileiro, com importantes autores em catálogo, sobretudo de literatura brasileira contemporânea (Hallewell, 2012; Sorá, 2010; Pereira, 2008 et all.).

Do ponto de vista do design, a editora foi tema de trabalhos com foco na atuação de capistas como Tomás Santa Rosa (Bueno, 2015; Cunha Lima \& Ferreira, 2005 et all.), Poty (Fontana, 2010) e Eugênio Hirsch (Nogueira, 2009), ou de breves comentários pontuais sobre aspectos específicos relacionados ao projeto visual dos livros. Padrões e variações nas capas de livros editados pela José Olympio nos anos de 1930 e 1940 foram analisados em trabalho já publicado por uma das autoras deste artigo (Fontana, 2018). Este estudo tem como objetivo descrever e analisar a linguagem gráfica utilizada nas coleções de livros publicadas pela editora nos anos de 1930, ampliando o conhecimento sobre a memória gráfica brasileira no período.

As duas primeiras coleções da José Olympio foram lançadas em 1934, ano em que se mudou para o Rio de Janeiro. A partir daí, o agrupamento de títulos foi recorrente no catálogo

Anais do $9^{\circ} \mathrm{CIDI}$ e $9^{\circ} \mathrm{CONGIC}$

Luciane Maria Fadel, Carla Spinillo, Anderson Horta, Cristina Portugal (orgs.)

Sociedade Brasileira de Design da Informação - SBDI Belo Horizonte | Brasil | 2019

ISBN 978-85-212-1728-2
Proceedings of the 9th CIDI and 9th CONGIC Luciane Maria Fadel, Carla Spinillo, Anderson Horta, Cristina Portugal (orgs.)

Sociedade Brasileira de Design da Informação - SBDI Belo Horizonte | Brazil | 2019

ISBN 978-85-212-1728-2 
da editora, com coleções pensadas por público, por temática, por gênero, por autor etc. Até o final do decênio, foram criadas oito coleções, nas quais foram publicados 101 títulos (tabela 1). Esse número representa quase $30 \%$ das obras lançadas pela editora no período analisado, que seriam 358 (Hallewell, 2012, p. 869).

Tabela 1. Coleções da José Olympio no decênio de 1930.

\begin{tabular}{l|c|c|c}
\hline Coleção & Início & Fim & $\begin{array}{c}\text { Volumes publicados } \\
\text { nos anos de 1930 }\end{array}$ \\
\hline Problemas Políticos Contemporâneos & 1934 & 1939 & 19 \\
\hline Menina e Moça (1a fase) & 1934 & 1934 & 5 \\
\hline Alfredo Pujol & 1935 & 1936 & 7 \\
\hline Obras Completas de Humberto de Campos & 1935 & 1940 & 32 \\
\hline Documentos Brasileiros & 1936 & dec. 1980 & 22 \\
\hline Série Obras Educativas & 1938 & {$[1951]$} & {$[7]$} \\
\hline Rubáiyát & 1938 & 1961 & 5 \\
\hline Pensamento Cristão & 1939 & 1942 & 4 \\
\hline \multicolumn{2}{l}{} & Total & 101 \\
\hline
\end{tabular}

Neste artigo, são consideradas coleções conjuntos de obras formalmente identificados como tal nos catálogos ou anúncios da editora ou nas próprias obras, assim como aquelas assim referidas em periódicos da época. Por isso, não foram analisadas aqui as obras de literatura brasileira contemporânea publicadas com capas padronizadas por Santa Rosa a partir de 1935 - objeto da análise de Cunha Lima \& Ferreira (2005). O tratamento e os agrupamentos feitos pela editora dessas obras variou nos anos de 1930 e também posteriormente: ora eram listadas como um grande conjunto, ora eram reunidas por gênero (conto ou romance), ora por autor, sem que se efetivasse o estabelecimento de uma coleção.

\section{Métodos e procedimentos de pesquisa}

A pesquisa realizada para este artigo, baseada sobretudo em fontes primárias, iniciou com a identificação e listagem das coleções publicadas pela José Olympio no decênio de 1930, o que foi executado consultando catálogos da editora, exemplares dos livros e o acervo bibliográfico da Biblioteca Nacional. Em seguida, foi feito o levantamento dos títulos de cada uma das coleções, o que permitiu a construção do corpus de obras para análise, além da sistematização de informações, como ano de início e fim e número de volumes publicados no período abordado.

O exame dos exemplares permitiu a construção de uma tabela sistematizando alguns parâmetros, tais como presença ou ausência de ilustrações, utilização de layout fixo ou variável, numeração e identificação dos volumes, formatos e cores de impressão (tabela 2). Foi então realizada a descrição analítica da linguagem e dos recursos gráficos utilizados nas capas (tendo como base Twyman, 1979 e Farias, 2016).

Foram realizados registros fotográficos digitais das capas de diversos volumes de cada coleção, etapa necessária para a análise de suas características visuais. Finalmente, o resultado dessas análises visuais foi cotejado com aspectos da história da editora e com o conteúdo de obras editadas. 
Fontana, C. F. \& Farias, P. L., | A linguagem gráfica das capas de coleções da Livraria José Olympio Editora no decênio de 1930: uma análise baseada em princípios do design da informação

\section{Resultados: as coleções da José Olympio nos anos 1930}

\section{Coleção Problemas Políticos Contemporâneos}

A coleção Problemas Políticos Contemporâneos foi a primeira lançada pela José Olympio, em meados de 1934. A maior parte de seus volumes é de autoria de líderes ou simpatizantes do movimento integralista, tais como Plinio Salgado e Miguel Reale.

As capas da coleção (figura 1), cujo autor é desconhecido, são impressas em três cores. Uma delas é usada para formar um padrão quadriculado, que ocupa a maior área da capa. A segunda cor forma uma tarja vertical posicionada na lateral esquerda e o preto é utilizado em textos e para dar destaque ao título, que aparece com letras vazadas em uma tarja horizontal posicionada no centro óptico do layout.

A diferenciação entre os volumes é obtida com a variação das cores do padrão quadriculado e da tarja da esquerda. A tarja do título aparece sempre em preto, utilizado também para as outras informações textuais: nome e volume da coleção, na parte superior; nome do autor, um pouco acima do título; e identificação da editora, no pé da capa.

Nos primeiros nove livros da coleção, todo o texto parece ter sido desenhado a mão. Isso muda a partir do décimo volume, no qual o lettering do título é substituído por composição com caracteres tipográficos. Os demais elementos textuais permanecem iguais, pois, possivelmente, a editora dispunha de clichês, reaproveitados de um volume a outro.

Entre os dezenove volumes, há outras pequenas variações, como a posição do número da edição, incluído quando alguns dos livros foram reeditados. O volume 11 , de 1935 , destoa dos demais, por ter todo o texto composto com caracteres tipográficos, usando letras visualmente diferentes das utilizadas como padrão.

Figura 1. Volumes iniciais da coleção Problemas Políticos Contemporâneos, de 1934, com o lettering feito à mão, e, à direita, o volume 14, de 1936, com o título composto com caracteres tipográficos.
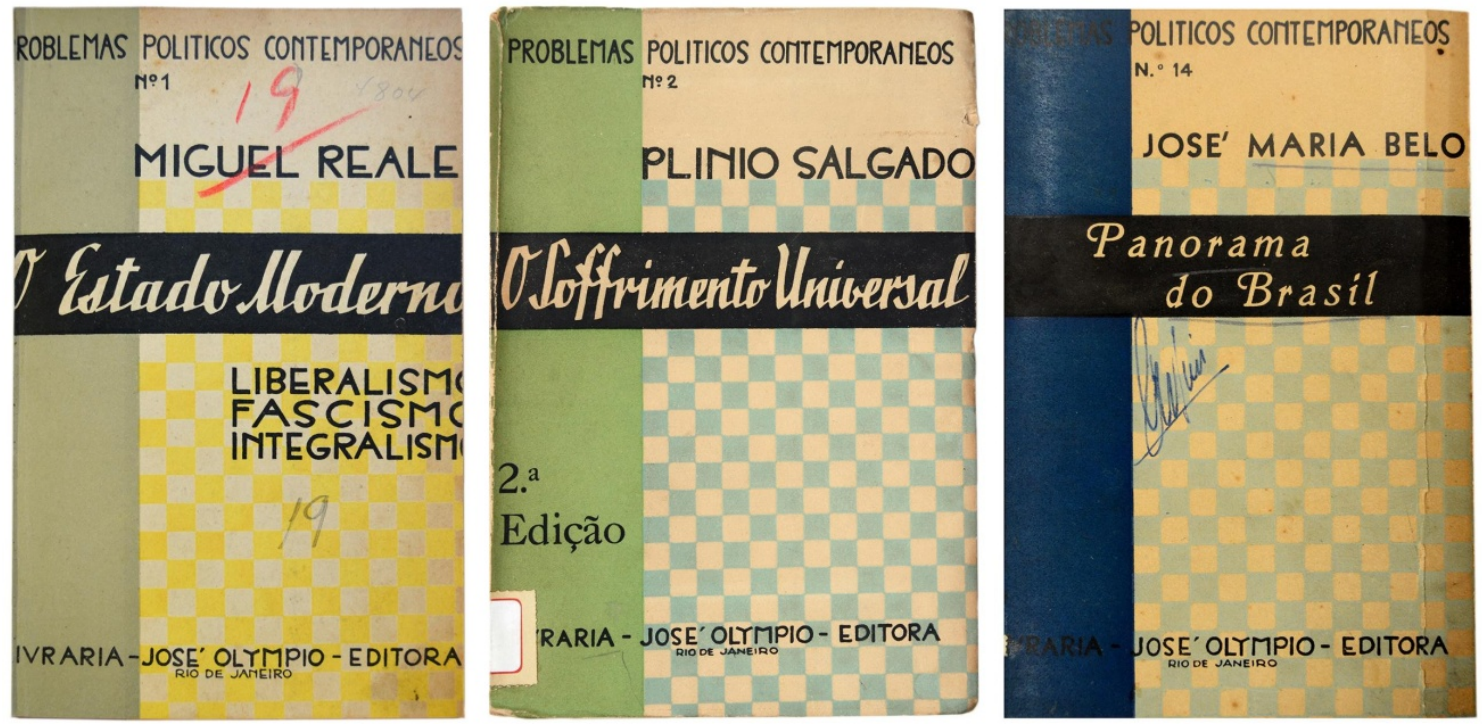


\section{Coleção Menina e Moça}

Menina e Moça foi a segunda coleção lançada pela José Olympio. Era dedicada a publicar romances curtos para meninas e adolescentes. A iniciativa, de início, foi efêmera, tendo sido lançados apenas cinco títulos no segundo semestre de 1934. Posteriormente a coleção foi retomada em outros quatro períodos - 1943, 1947, 1951 e 1964 - e a cada nova fase corresponde uma apresentação gráfica diferente para os livros.

Os romances da primeira fase da Menina e Moça foram todos traduzidos do francês, escolhidos entre obras originalmente editadas na Bibliothèque de Suzette, coleção que vinha sendo publicada pela editora parisiense Gautier et Languereau desde 1919. A coleção francesa forneceu à da José Olympio as obras a serem traduzidas, e também parece ter servido de modelo para seu primeiro projeto de capa, cujo autor é desconhecido.

As capas da José Olympio (figura 2), impressas em três cores, trazem o nome da coleção dentro de um box na parte superior, assim como a coleção francesa (figura 3). As demais informações seguem a mesma disposição em ambos os layouts: autor e título mais ao centro e identificação da editora na parte inferior. Completam a capa motivos florais: uma vinheta logo acima do nome da editora e um festão, que nas capas da Bibliothèque de Suzette pende a partir do box superior e na versão brasileira foi deslocado para as laterais.
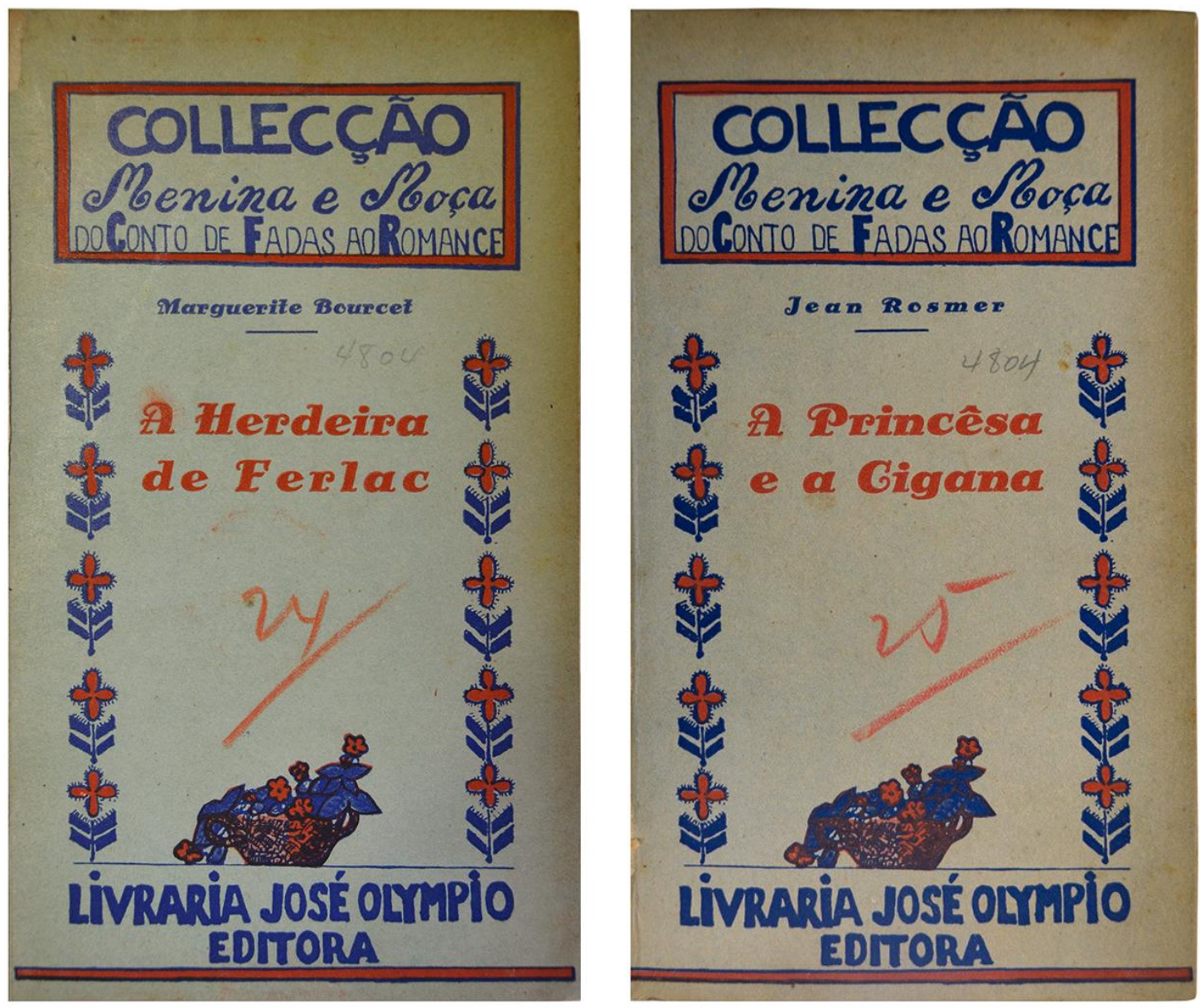
Fontana, C. F. \& Farias, P. L., | A linguagem gráfica das capas de coleções da Livraria José Olympio Editora no decênio de 1930: uma análise baseada em princípios do design da informação

Figura 3. Capa da coleção Bibliothèque de Suzette, 1923

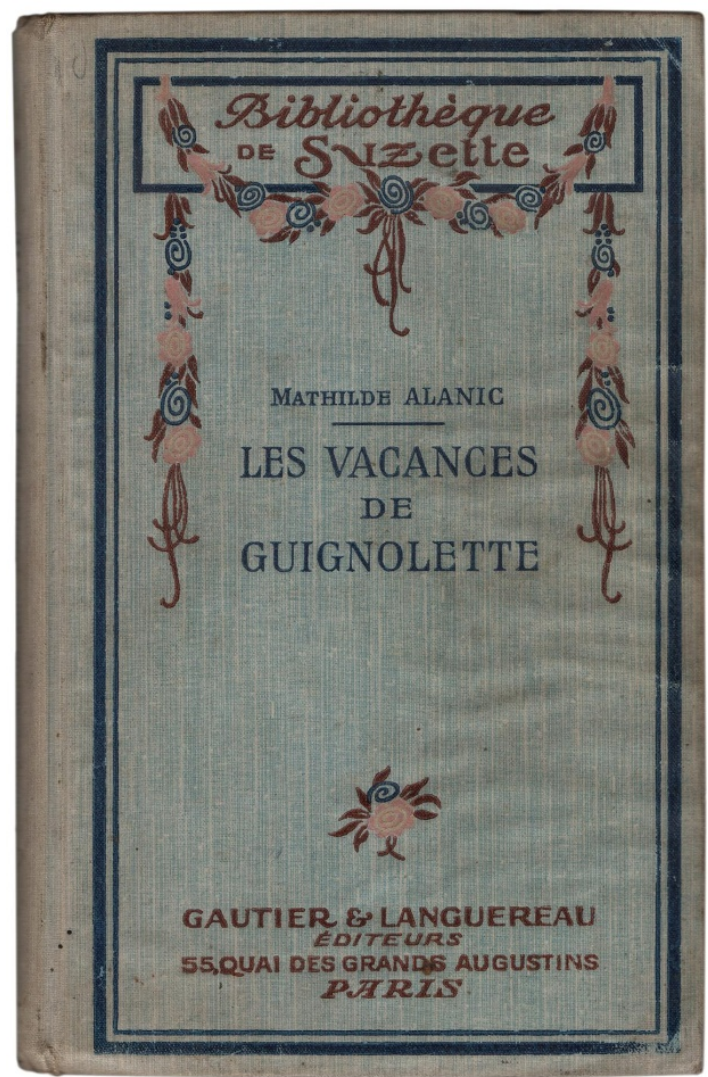

Chama a atenção, nas capas da José Olympio, a execução um tanto informal do layout. Com exceção do título e do nome do autor, impressos com tipos móveis e substituídos a cada volume, os demais elementos foram desenhados a mão. Os traços são bastante irregulares, sobretudo no box com o nome da coleção (figura 4), no qual tanto o traçado das letras como seu espaçamento são pouco uniformes, e nas duas letras M ligeiramente diferentes usadas no logotipo (figura 5). Resta saber se a imperícia da capa se deve a ter sido feita de forma amadora ou se propositadamente encomendada a mãos infantis, como forma de se aproximar do público leitor.

Figura 4. Box com o título e o slogan da coleção Menina e Moça, 1934.

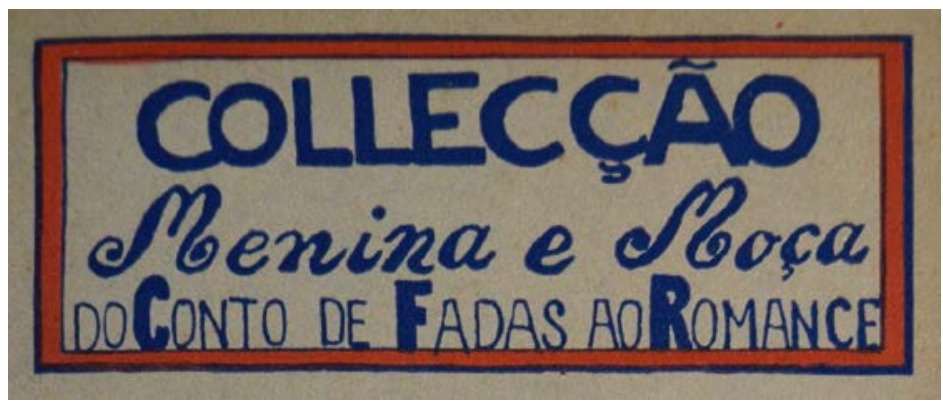

Figura 5. Logotipo da coleção na quarta capa de volume de 1934

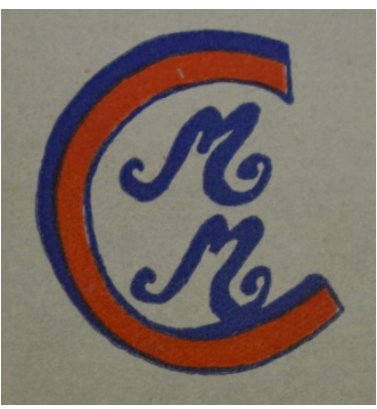

Em termos de acabamento as coleções se diferenciavam. A francesa era editada em volumes com capa dura e os livros da José Olympio eram brochuras, em formato aproximado 
Fontana, C. F. \& Farias, P. L., | A linguagem gráfica das capas de coleções da Livraria José Olympio Editora no decênio de 1930: uma análise baseada em princípios do design da informação

de $11,5 \times 18,5 \mathrm{~cm}$. Os volumes custavam $3 \$ 000$, valor bem mais baixo que o de um romance adulto, o que talvez explique a baixa qualidade do papel utilizado ${ }^{1}$.

\section{Coleção Alfredo Pujol}

Nas obras publicadas como parte da coleção Alfredo Pujol, datadas de 1935 e 1936, não há menção ao fato de pertencerem a um conjunto, o que também não fica evidente nas capas dos livros, que não seguem qualquer padrão gráfico. Nos catálogos e anúncios da José Olympio a coleção também não deixou vestígios, pois seu nome não é mencionado e as obras não são apresentadas em conjunto. Matérias de jornais da época, no entanto, dão bastante destaque à coleção $^{2}$, comparando-a, em importância, à Brasiliana da Companhia Editora Nacional ${ }^{3}$.

Em termos gráficos, nas capas da Alfredo Pujol não há, como mencionado, nenhum indício de que as obras faziam parte de uma coleção (figura 6). A única característica em comum dos volumes é o formato, $14,5 \times 22,5 \mathrm{~cm}$, maior que o mais comumente adotado pela José Olympio à época. As capas são impressas em duas ou três cores, e em algumas capas aparecem áreas de cor, fios ou molduras. Nenhuma traz elementos pictóricos.
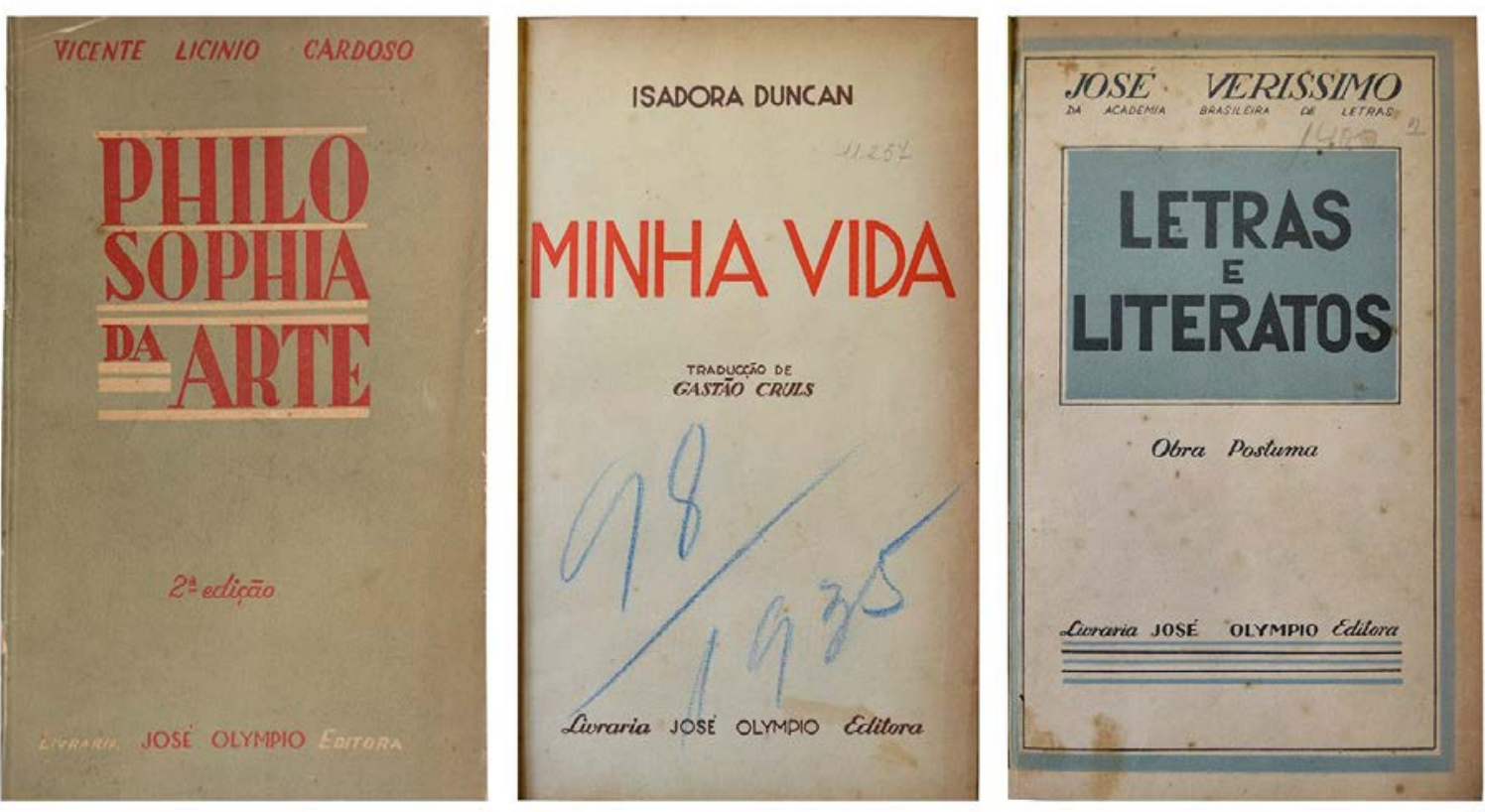

Ainda que as capas não compartilhem uma linguagem gráfica uniforme, a disposição dos elementos verbais é sempre a mesma: nome do autor no topo, título do livro em corpo maior no centro óptico e nome da editora no pé, todos centralizados. O lettering dos títulos é, no geral, o elemento de maior destaque do layout e não há desenhos de letras que se repitam entre os volumes, num esforço de variação.

\footnotetext{
${ }^{1}$ Em catálogo da editora de novembro de 1936 os romances são anunciados por valores entre $6 \$ 000$ e $10 \$ 000$. O papel dos volumes da coleção Menina e Moça examinados encontra-se muito oxidado e quebradiço, em situação pior de conservação do que aquela de outros livros publicados pela editora no mesmo período.

${ }^{2}$ Por exemplo, "Registros Bibliográficos", Diário de Notícias, 9 fev. 1936, p. 15; "Bibliografia", Gazeta de Notícias, 9 fev. 1936, p. 10.

3 "Coleção Alfredo Pujol", Diário de Notícias, 22 mar. 1936, p. 19. Esta matéria menciona como próximos lançamentos da Alfredo Pujol títulos que acabaram sendo publicados em outra coleção da editora, a Documentos Brasileiros, lançada em 1936. Ainda que o perfil das duas coleções não seja o mesmo, é possível que a Alfredo Pujol tenha sido descontinuada para dar lugar à Documentos Brasileiros.
} 
Nenhum dos volumes da coleção traz o crédito do capista, porém, por meio de outras fontes - periódicos da época e recibos assinados pelo artista gráfico ${ }^{4}$-, foi possível saber que Santa Rosa foi o autor de seis das sete capas da coleção: Filosofia da Arte, A Vida Inquieta de Raul Pompeia e Educação para a Democracia, de 1935, e Machado de Assis, Minha Vida e Letras e Literatos, editados em 1936.

\section{Coleção Obras Completas de Humberto de Campos}

Humberto de Campos entrou para o catálogo da José Olympio em 1933 e, como autor de grandes best-sellers do período, ajudou a consolidar a editora, financeira e culturalmente. Apesar de algumas tentativas anteriores de padronizar as capas das muitas obras do escritor no total, a José Olympio publicou quarenta títulos de sua autoria, alguns deles com diversas edições em um mesmo ano - um layout padrão começou a ser efetivamente adotado em 1935, quando os livros passaram a ser agrupados na coleção aqui analisada.

As capas da coleção foram impressas em duas paletas diferentes, utilizadas para distinguir as obras das duas facetas do escritor: verde para as obras "sérias" - de literatura, crítica e memórias - e vermelho para as obras de cunho satírico, assinadas com o pseudônimo Conselheiro XX (figura 7).

Figura 7. Capas da coleção Obras Completas de Humberto de Campos, 1935 e 1936.
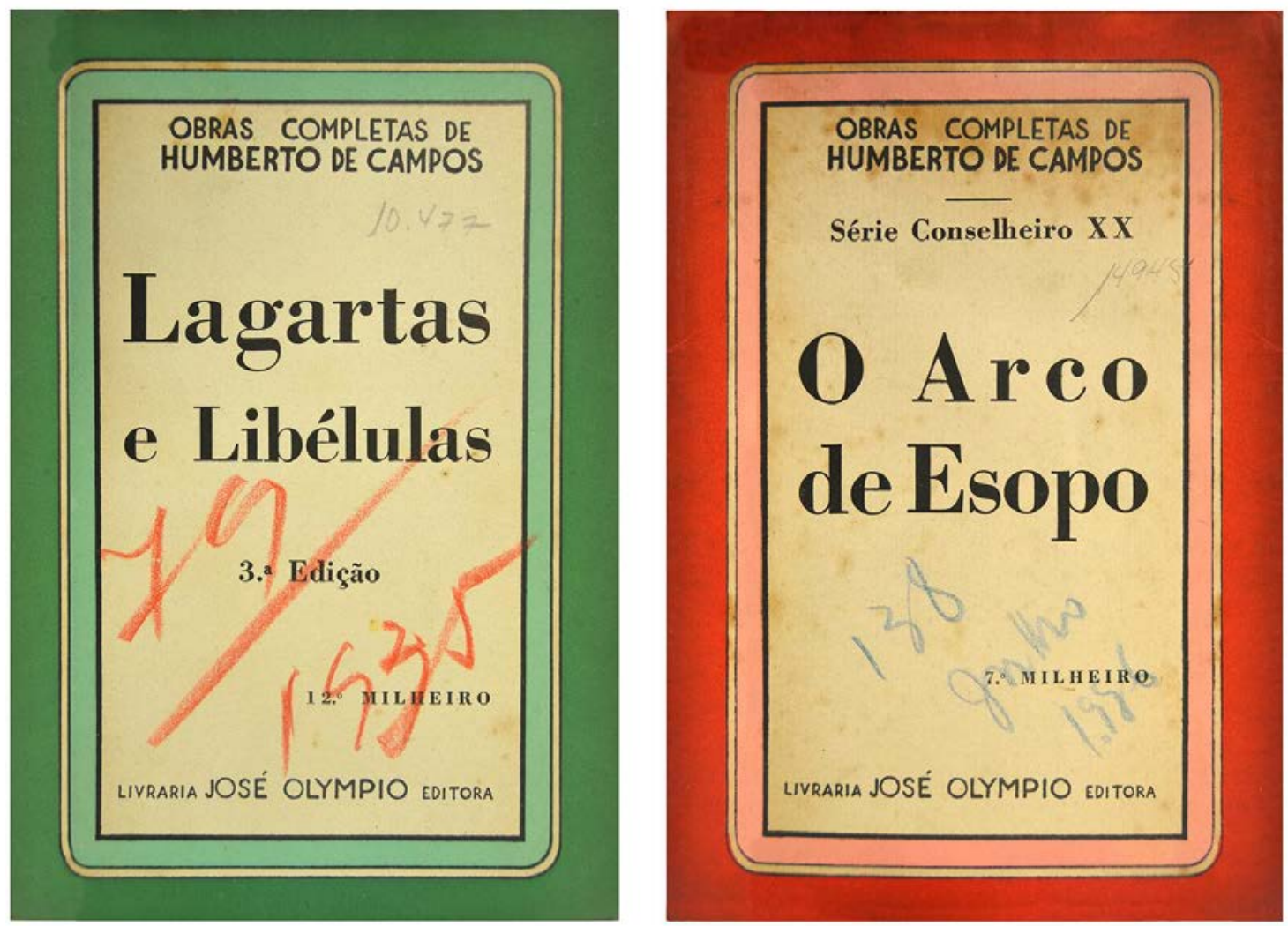

Impressas em três cores, as capas apresentam uma série de molduras concêntricas delimitadas por linhas em preto. A moldura mais externa é preenchida com uma das cores, verde ou vermelho, que sangra a área da capa. Uma segunda cor - verde mais claro na primeira variação e rosa na outra - é usada em outra moldura, mais central, dentro da qual uma área sem preenchimento é usada para as informações textuais: coleção em cima, título ao

${ }^{4}$ Para mais detalhes sobre os recibos de Santa Rosa, ver Fontana, 2018. 
centro, informações sobre a edição e/ou milheiro logo abaixo e assinatura da editora no pé. No caso das obras satíricas, imediatamente abaixo da coleção aparece "Série Conselheiro XX".

O nome da coleção e da editora aparecem sempre grafados em letras sem serifa desenhadas a mão, mas idênticas em todos os volumes, o que permite supor que era utilizado sempre o mesmo clichê. Já o título do livro, as informações sobre a edição e/ou o milheiro, além da série - ou seja, todos os elementos que variavam - eram compostos com tipos móveis. Inicialmente, os tipos escolhidos eram serifados, mas com o passar do tempo houve variações e diferentes famílias tipográficas foram utilizadas.

Como nas outras coleções apresentadas até aqui, esta também não traz o crédito do capista nos volumes. É possível, no entanto, que o projeto seja de Santa Rosa. A atribuição se baseia em duas evidências. A primeira é uma resenha em jornal de 1936 sobre a publicação da segunda edição da obra $O$ Mealheiro de Agripa, na qual se registra a reedição, informando que fora incluída nas Obras Completas. O texto, além de elogiar a apresentação gráfica do volume, informa que a capa é de Santa Rosa ${ }^{5}$. A segunda evidência é um recibo assinado por Santa Rosa em junho de 1935 pela capa de "obras de Humberto de Campos" 6.

\section{Coleção Documentos Brasileiros}

A coleção Documentos Brasileiros, lançada em 1936 sob a direção de Gilberto Freyre, foi a brasiliana da José Olympio. Dedicada à publicação de estudos sobre o Brasil, à moda de outras coleções então disponíveis no mercado, ajudou a marcar a posição da editora como instituição culturalmente relevante, aquela pela qual "todo escritor desejava ser editado" (Sorá 2010, p. 29).

As capas da coleção Documentos Brasileiros (figura 8) são de autoria de Santa Rosa. Esta foi a primeira coleção da editora a trazer o crédito do capista no miolo do volume. O projeto, simples e sóbrio, é, talvez, um dos mais conhecidos do artista gráfico, por ter permanecido em uso por cerca de três décadas e, também, pelo destaque dado à coleção na história da editora.

A disposição dos elementos textuais da capa segue o mesmo padrão adotado nas outras coleções lançadas até então, com o acréscimo de uma informação que não aparece em nenhuma das anteriores: o nome de seu diretor, posicionado logo após a identificação da coleção, no topo da capa.

As capas eram impressas em duas cores: uma mais escura (marrom no primeiro volume e preto nos subsequentes) e uma segunda cor variável, utilizada no título e em uma barra após o nome da coleção, auxiliando na diferenciação dos volumes.

Assim como em outras coleções, os elementos que se repetiam nas capas eram impressos, possivelmente, a partir de clichês, e os demais eram compostos para cada volume. Nos primeiros livros, o título e o nome do autor eram feitos à mão, mas posteriormente esse lettering deu lugar a composições com caracteres tipográficos. Em ambos os casos, o desenho das letras do título variava, sendo, junto com a segunda cor, um fator de particularização dos volumes.

A Documentos Brasileiros foi a coleção mais longeva da editora, permanecendo em catálogo até os anos de 1980. A forma de apresentação dos nomes da coleção e da editora permaneceu inalterada até o fim dos anos de 1950, quando, apesar de a estrutura da capa ter sido mantida, o lettering de Santa Rosa foi aos poucos substituído por composições tipográficas. Ao longo dos anos, variaram também a dimensão e a posição do único elemento pictórico da capa, a palmeira, símbolo da coleção.

\footnotetext{
5 "Registro Literário", A Federação, RS, 16 jun. 1936, p. 3.

${ }^{6}$ Recibo datado de $1^{\circ}$ de junho de 1935 , Coleção José Olympio, Biblioteca Nacional.
} 
Fontana, C. F. \& Farias, P. L., | A linguagem gráfica das capas de coleções da Livraria José Olympio Editora no decênio de 1930: uma análise baseada em princípios do design da informação

Figura 8. Capas de Santa Rosa para a coleção Documentos Brasileiros, 1936 e 1937.
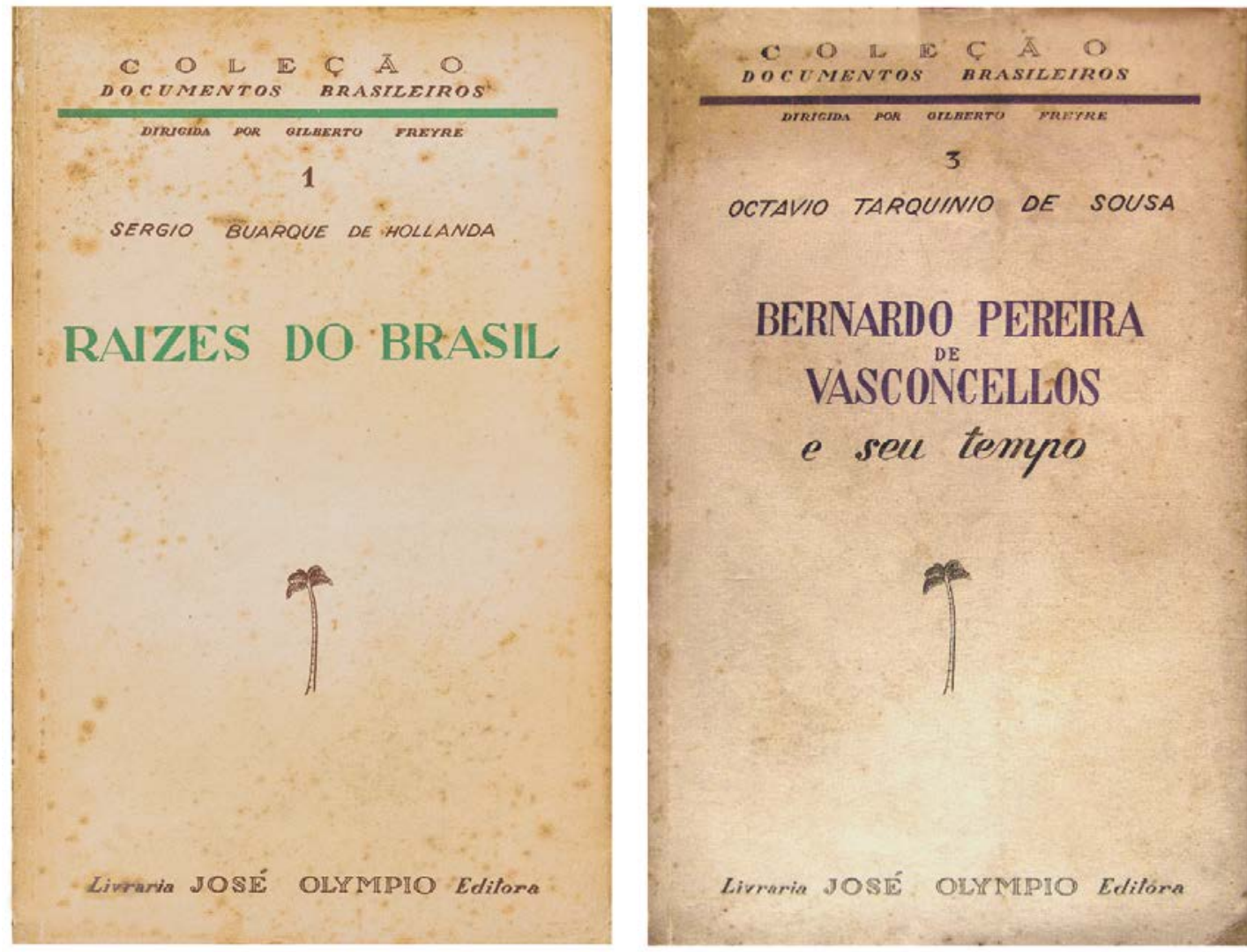

\section{Série Obras Educativas}

O projeto das capas da Série Obras Educativas foi utilizado pela primeira vez em 1936, no livro Educação dos Pais. Não é possível saber se, nessa época, a editora já considerava a obra como início e/ou parte de um conjunto, pois no exemplar não há referência a série ou coleção.

O desenho de capa ressurge em 1938 em ao menos outras três publicações, ainda sem qualquer informação sobre a coleção, cujas obras tratavam de temas relacionados ao comportamento humano. A coleção, de fato, parece ter sido formalizada apenas em 1940, quando o título Série Obras Educativas passou a ser mencionado em periódicos ${ }^{7}$. Nos livros, as primeiras listagens agrupando as obras como parte de uma série ainda aparecem sem um nome para ela, precedidas apenas por "volumes publicados nesta série"8.

A base do que seria a unidade gráfica das capas já havia sido estabelecida, de qualquer maneira, em 1936, e a autoria pode ser mais uma vez atribuída a Santa Rosa, responsável pelo layout de Educação dos Pais ${ }^{9}$.

Utilizando três cores, o espaço da capa é dividido em quatro faixas horizontais impressas em duas dessas tintas. Sobre a primeira e a terceira faixas, sempre em tons mais claros, 0 preto é utilizado para o nome do autor e para linhas de texto que descrevem o conteúdo do livro. Na segunda faixa, impressa em tom mais escuro no centro óptico da capa, fica o título do livro, vazado em branco ou na cor mais clara. O mesmo acontece para o nome da editora na última faixa de cor, no pé (figura 9).

\footnotetext{
${ }^{7}$ Entre outros, "Movimento Literário", Carioca, 31 ago. 1940, p. 9, e "Livros Novos", O Cruzeiro, 1ํㅡov. 1941, p. 16.

${ }^{8}$ Por exemplo, nas páginas iniciais da segunda edição de O Acanhamento e a Timidez, de 1940.

${ }^{9}$ Recibo datado de 16 setembro de 1936, Coleção José Olympio, Biblioteca Nacional.
} 
Figura 9. Capa de Santa Rosa para Educação dos Pais, 1936, e dois volumes da Série Obras Educativas publicados em 1938 seguindo o mesmo projeto.
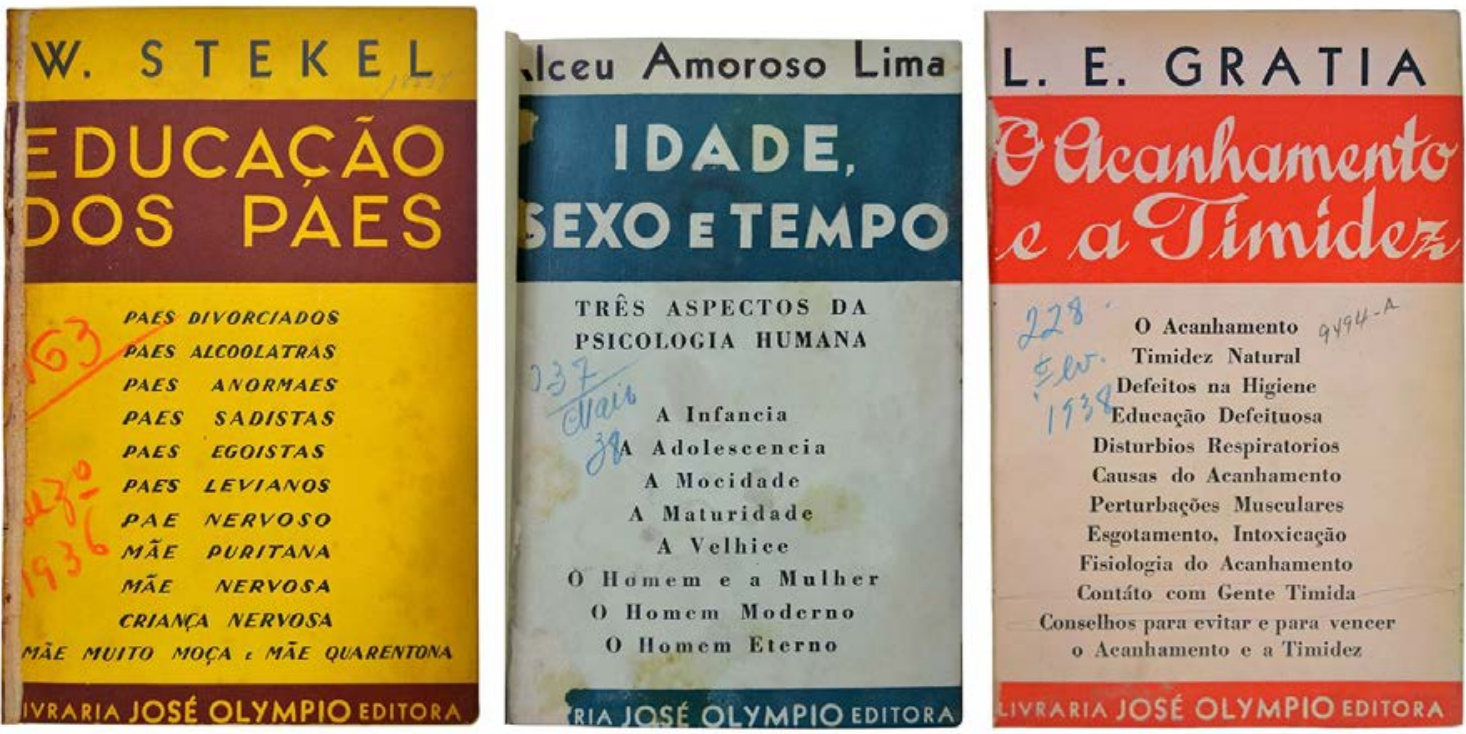

Como em outras coleções, a diferenciação dos volumes é obtida com a troca das cores exceto o preto - e do desenho das letras do título, sempre feito à mão. Na capa de 1936 a descrição do conteúdo também utiliza caracteres desenhados, porém esse lettering foi substituído por tipos móveis já a partir de 1938.

Muitos dos volumes da coleção foram obras de sucesso comercial, com diversas reedições ao longo dos anos. Até meados do decênio de 1950 as novas edições eram indicadas acrescentando-se uma quarta cor para a impressão do número da edição, em geral em vermelho sob o texto descritivo. Posteriormente o layout padronizado foi abandonado e novas reedições passaram a ser publicadas com capas sem relação umas com as outras.

\section{Coleção Rubáiyát}

Esta é mais uma das coleções da José Olympio que parecem ter ido se moldando aos poucos, conforme os volumes foram sendo lançados e agrupados. Os dois primeiros títulos - Rubáiyát, de Omar Kháyyám ${ }^{10}$, e O Jardim das Carícias, de Franz Toussaint - foram publicados em 1938. Nesse primeiro momento, contudo, Rubáiyát ainda não era utilizado como nome da coleção, o que só passou a ocorrer em 1943, após a adoção temporária do título Série de Poemas Orientais.

Mais uma vez, o modelo de capa é de Santa Rosa, que optou por uma composição centralizada para os elementos verbais e pictóricos, envoltos por uma moldura ornamentada (figura 10). Uma novidade da coleção é o destaque dado ao nome dos tradutores, posicionado no topo da capa. Na sequência aparecem o título do volume, em corpo maior, e o nome do autor, em corpo menor que o do tradutor ${ }^{11}$. Completam a capa uma vinheta e o nome da editora.

\footnotetext{
${ }^{10}$ A edição de 1938 foi, na verdade, a terceira da tradução de Octávio Tarquínio de Souza, que já havia sido editada em 1928, pela Imprensa Nacional, e em 1935, pela própria José Olympio, com capa de Gilberto Trompowsky.

${ }^{11}$ Essa estrutura foi mantida nos livros publicados até 1942, sendo depois invertida, com o nome do autor passando para a parte de cima, em corpo maior que o usado para o do tradutor.
} 
Figura 10. Capas da coleção Rubáiyát, Santa Rosa, 1938.
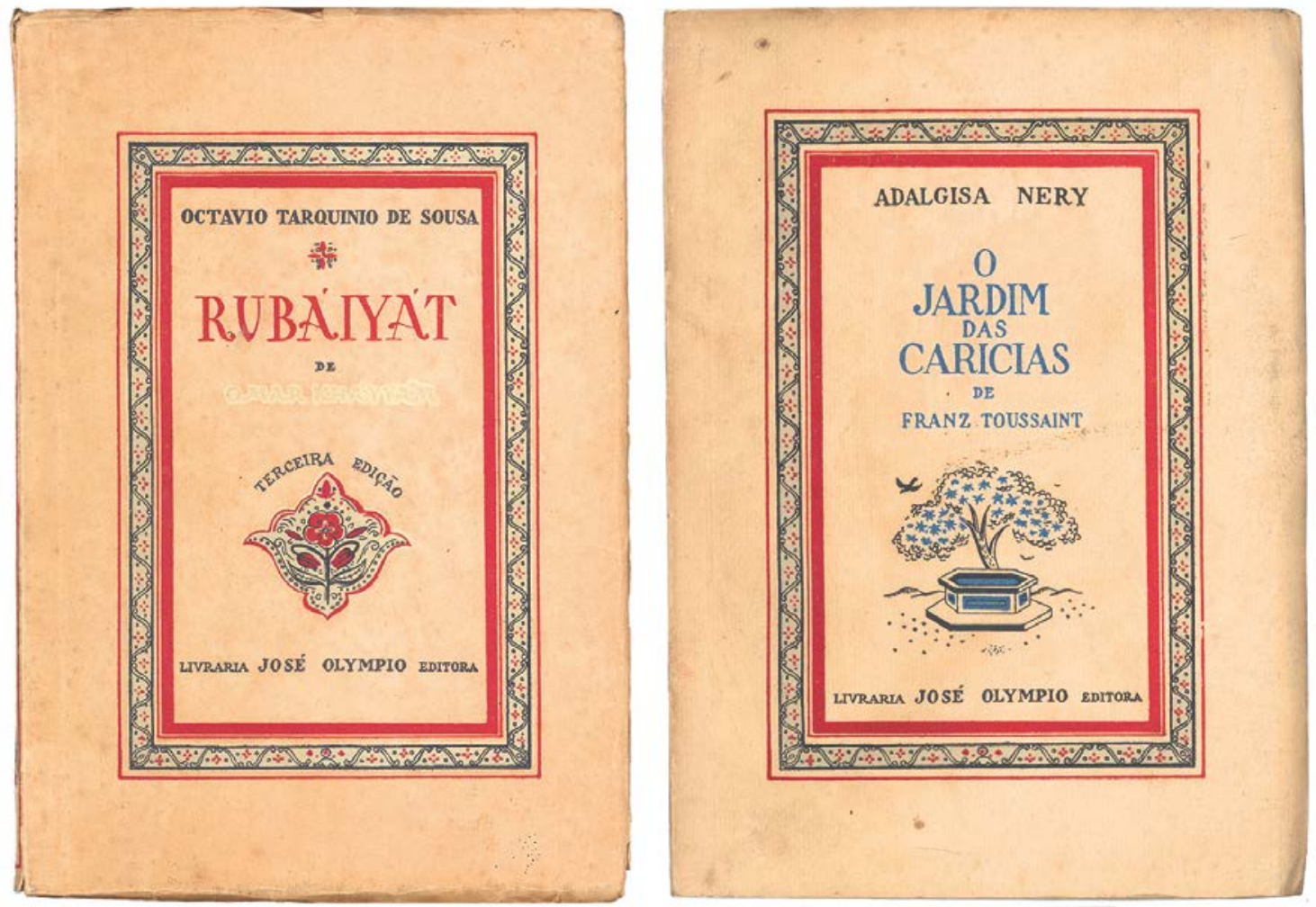

A capa do primeiro volume foi impressa em três cores, e, a partir do segundo, foram utilizadas quatro cores, aproveitadas também na lombada decorada e em vinhetas na quarta capa. Mais uma vez, a variação das cores de impressão foi utilizada como elemento de diferenciação dos volumes, junto com a vinheta, esta sempre relacionada ao conteúdo do livro.

A Rubáiyát foi uma das coleções mais duradouras da José Olympio, tendo se mantido em catálogo, com o mesmo formato e o mesmo layout de capa, até o início dos anos de 1960, chegando a quase cinquenta volumes. Com o passar do tempo, o projeto de capa sofreu inúmeras pequenas variações, sendo possível encontrar os diversos elementos em diferentes arranjos. Também eram variáveis os tipos utilizados. A moldura desenhada por Santa Rosa manteve-se intacta, no entanto, até o último volume publicado, ainda que outros artistas gráficos tenham assumido a tarefa de executar o projeto.

\section{Coleção Pensamento Cristão}

A coleção Pensamento Cristão foi a última a ser iniciada pela José Olympio no decênio de 1930, tendo seus quatro primeiros volumes publicados a partir de julho de 1939. A iniciativa não durou muito tempo e apenas mais duas obras foram lançadas, em 1941 e 1942.

As capas trazem, no topo, o nome da coleção e de seu diretor - padre Lacroix. Uma barra dupla separa essas informações do número do volume e do nome do autor, logo abaixo. O elemento de maior destaque é sempre o título, posicionado no centro óptico da capa, sobre o traço horizontal de uma cruz formada pelo espaço sem impressão entre quatro retângulos posicionados a partir dos cantos e que cobrem quase toda a área da capa. O nome da editora vem no pé (figura 11). 

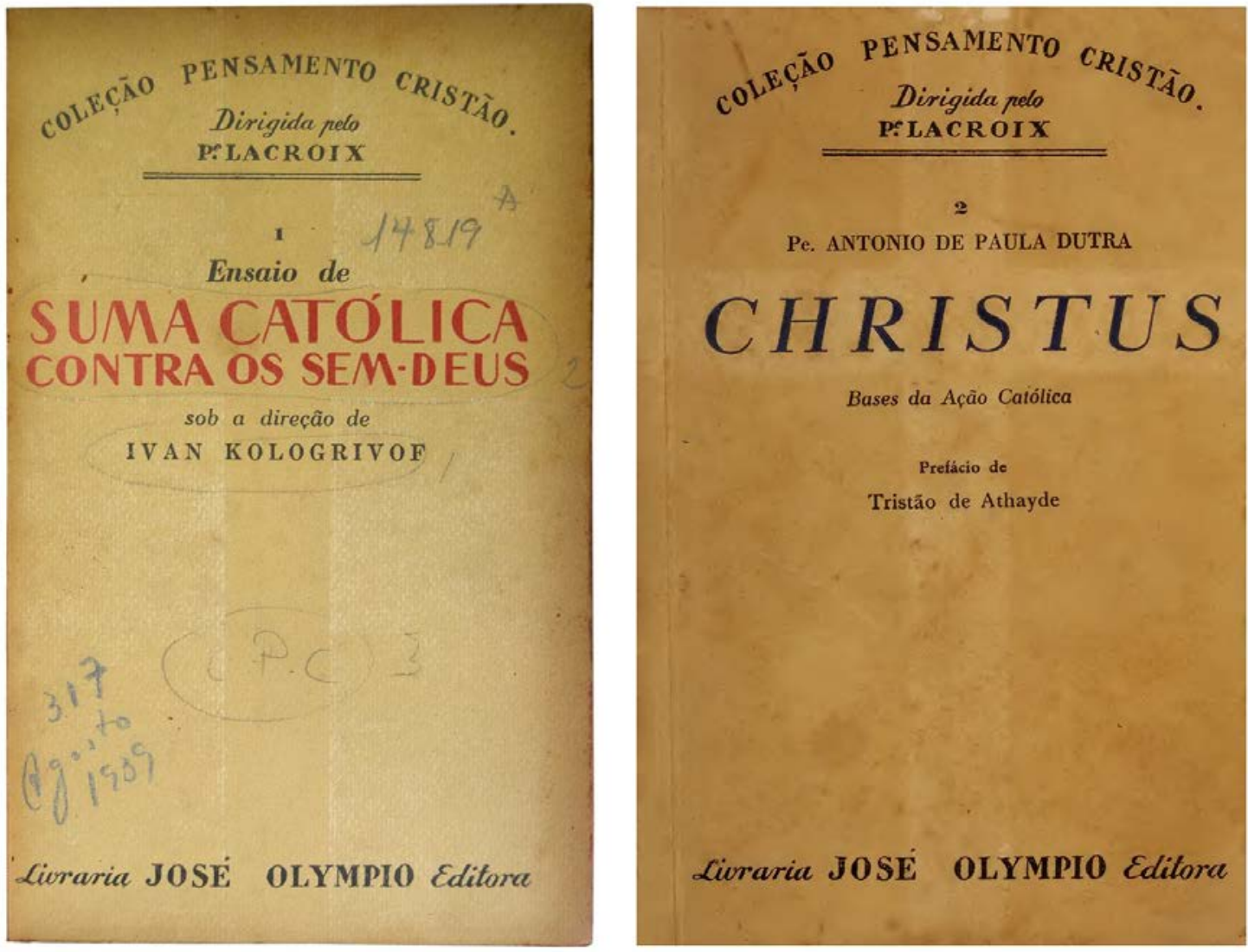

São utilizadas três cores na impressão das capas: uma delas variável, para o título, preto para os demais elementos textuais e uma terceira cor clara para os retângulos ${ }^{12}$.

Os exemplares não trazem o crédito do responsável pelo projeto da capa. Sua linguagem gráfica, no entanto, se assemelha à da coleção Documentos Brasileiros, da qual empresta a estrutura. Por esse motivo, e também pelo desenho de parte das letras utilizadas, que repetem modelos por ele utilizados em outros trabalhos, é possível que o projeto da capa dessa coleção seja também de Santa Rosa.

\section{Discussão: Características visuais das coleções da José Olympio no decênio de 1930}

A análise da linguagem gráfica das oito coleções publicadas pela José Olympio nos anos de 1930 revelou que sete delas contam com layout padronizado de capa, isto é, com capas contendo elementos que se repetem para dar uniformidade gráfica ao conjunto. Isso não implicava, contudo, a repetição de capas idênticas, pois diversas estratégias eram adotadas para diferenciar um volume do outro, individualizando-os sem que se perdesse a noção de conjunto.

A tabela 2, construída com base no exame e detalhamento das características visuais das capas, sistematiza os elementos analisados neste artigo.

\footnotetext{
${ }^{12}$ Com a oxidação do papel no decorrer dos anos, essas áreas de cor e a própria cruz se tornaram quase imperceptíveis nos exemplares examinados.
} 
Fontana, C. F. \& Farias, P. L., | A linguagem gráfica das capas de coleções da Livraria José Olympio Editora no decênio de 1930: uma análise baseada em princípios do design da informação

Tabela 2. Características visuais das coleções da Livraria José Olympio Editora no decênio de 1930.

\begin{tabular}{|c|c|c|c|c|c|c|c|}
\hline & Layout & $\begin{array}{l}\text { Elementos } \\
\text { pictóricos }\end{array}$ & \begin{tabular}{|c|}
$\begin{array}{c}\text { Volumes } \\
\text { numerados }\end{array}$ \\
\end{tabular} & \begin{tabular}{|c|} 
Identificada \\
nos livros
\end{tabular} & Formato & \begin{tabular}{|c|} 
Cores de \\
impressão
\end{tabular} & Capista \\
\hline $\begin{array}{l}\text { Problemas Políticos } \\
\text { Contemporâneos }\end{array}$ & padrão & não & $\operatorname{sim}$ & sim & $\begin{array}{l}12 \times 19 \\
\text { (refilado) }\end{array}$ & \begin{tabular}{|c|}
3 (preto + \\
2 variáveis)
\end{tabular} & anônimo \\
\hline $\begin{array}{l}\text { Menina e Moça } \\
\text { (1ः fase) }\end{array}$ & padrão & sim & não & sim & $11,5 \times 18,5$ & 3 (fixas) & anônimo \\
\hline Alfredo Pujol & variável & não & não & não & $14,5 \times 22,5$ & $\begin{array}{c}2 \text { ou } 3 \\
\text { (variáveis) }\end{array}$ & Santa Rosa \\
\hline $\begin{array}{l}\text { Obras Completas de } \\
\text { Humberto de Campos }\end{array}$ & padrão & não & não & $\operatorname{sim}$ & $12,8 \times 18,8$ & 3 (fixas) & Santa Rosa \\
\hline Documentos Brasileiros & padrão & $\operatorname{sim}$ & $\operatorname{sim}$ & $\operatorname{sim}$ & $15 \times 23$ & $\begin{array}{l}2 \text { (preto + } \\
1 \text { variável) }\end{array}$ & Santa Rosa \\
\hline Série Obras Educativas & padrão & não & não & \begin{tabular}{|c|} 
não nos anos \\
de 1930
\end{tabular} & $14 \times 20$ & $\begin{array}{c}3 \\
\text { (variáveis) }\end{array}$ & Santa Rosa \\
\hline Rubáiyát & padrão & sim & \begin{tabular}{|c|} 
não nos anos \\
de 1930
\end{tabular} & \begin{tabular}{|c|} 
não nos anos \\
de 1930
\end{tabular} & $13,3 \times 19,2$ & $\begin{array}{c}3 \text { ou } 4 \\
\text { (variáveis) }\end{array}$ & Santa Rosa \\
\hline Pensamento Cristão & padrão & sim & $\operatorname{sim}$ & sim & $\begin{array}{c}12,1 \times 18,5 \\
\text { (refilado) }\end{array}$ & \begin{tabular}{|c|}
3 (preto + \\
2 variáveis)
\end{tabular} & [Santa Rosa] \\
\hline
\end{tabular}

A disposição dos elementos textuais segue um padrão em quase todas as capas de coleções, e as informações são apresentadas na seguinte sequência, de cima para baixo: nome da coleção, número do volume (quando há), nome do autor, título, número da edição (mais comum em reedições) e nome da editora (figura 12). Outros elementos, menos frequentes, são o subtítulo - logo após o título, quando ocorre -, o diretor da coleção (apenas em Documentos Brasileiros e Pensamento Cristão) e o nome do tradutor (somente em Rubáiyát).

Figura 12. Disposição dos elementos textuais em capas de coleções da José Olympio nos anos de 1930.

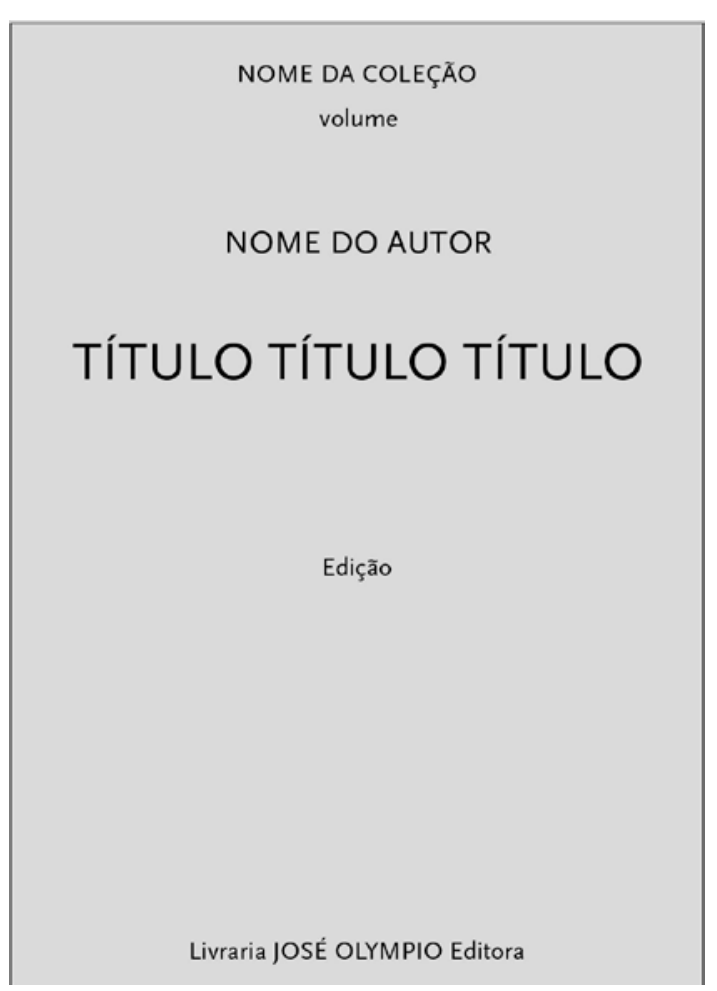


Nos anos de 1930, são poucos os elementos pictóricos utilizados nas capas de coleções da José Olympio, predominando os elementos textuais e esquemáticos. Apenas as coleções Menina e Moça, Documentos Brasileiros e Rubáiyát apresentam elementos pictóricos nas capas. Nos dois primeiros casos é utilizada a mesma vinheta em todos os volumes e somente a Rubáiyát conta com uma vinheta produzida especialmente para cada livro, a qual guarda relação com o conteúdo da obra.

Todas as coleções da José Olympio analisadas adotam formatos padronizados para os volumes, porém há bastante variação entre elas, não existindo um formato predominante. As medidas variam de $11,5 \times 18,5 \mathrm{~cm}$ na coleção com menor formato, proporcionalmente mais estreito (Menina e Moça), e $15 \times 23 \mathrm{~cm}$ naquela com maiores dimensões (Documentos Brasileiros).

Em termos do número de cores utilizadas na impressão, também não há um padrão entre as coleções. Quatro delas, ou metade, utilizavam sempre três cores. Mesmo dentro das coleções podiam ocorrer variações entre os volumes.

O método de impressão dominante na capa das coleções é o tipográfico. Os elementos que se repetiam, como o nome da coleção e a assinatura da editora, eram impressos, possivelmente, a partir de clichês, guardados e reutilizados. Já os elementos variáveis, tais como título e nome do autor, eram desenhados ou compostos a cada volume. Em parte das coleções, com o passar do tempo, elementos textuais originalmente desenhados à mão passaram a ser compostos com tipos móveis.

Apenas duas coleções têm a autoria da capa explícita nos livros. Em ambos os casos, o artista gráfico identificado é Tomás Santa Rosa, responsável pelas capas da Documentos Brasileiros e da Rubáiyát. Ao que tudo indica, uma vez estabelecido o modelo, a composição e a execução de volumes posteriores podiam ser assumidas por outro artista gráfico.

\section{Conclusões}

A estruturação de coleções foi uma estratégia utilizada pela José Olympio para a organização dos títulos de seu catálogo e sua oferta aos leitores desde o início da história da editora. Acompanhando o processo de desenvolvimento do catálogo, e das coleções em particular, observa-se que elas não necessariamente eram planejadas com diretrizes claras desde o início. Em muitos casos, pelo contrário, as coleções parecem ter ido se formando aos poucos, à medida que as obras eram lançadas. Em termos editoriais, isso significa que os livros de uma coleção podem formar um conjunto mais ou menos coeso, o que, por sua vez, graficamente, pode se traduzir em uma maior ou menor uniformidade visual entre as capas.

As soluções gráficas e visuais adotadas consideravam a necessária etapa de exposição e comercialização dos volumes, e a padronização das capas servia ao estabelecimento de uma identidade visual, auxiliando na identificação dos livros pelos leitores. Há coleções com acabamento mais sofisticado, certamente visando agradar a um público mais refinado, e outras pensadas para baratear o preço dos volumes, aumentando o número de leitores.

Em termos gráficos, ainda que na quase totalidade das coleções o editor tenha optado por um layout padronizado, os projetos quase sempre permitiam variabilidade entre os volumes, de modo que cada um apresentava soluções individuais. Das oito coleções analisadas, apenas uma, Menina e Moça, mantém todos os elementos inalterados nos diversos volumes, trocandose apenas o título e o nome do autor, impressos sempre com os mesmos tipos.

Um método recorrentemente empregado para a uniformização visual das capas das coleções foi a repetição de elementos gráficos, como bordas, vinhetas ou áreas de cor. A editora muito possivelmente conservava prontos os clichês que serviam de matrizes de impressão de elementos recorrentes nas capas, mantendo-os, assim, idênticos nos diversos volumes. 
A análise da linguagem gráfica mostrou que a variação das cores de impressão foi 0 principal recurso adotado para diferenciar os volumes das coleções, eventualmente acompanhada pelo uso de elementos esquemáticos, ou, mais raramente, pictóricos, além de variações nas formas de letras, principalmente naquelas usadas para os títulos dos livros.

As figuras apresentadas neste artigo mostram exemplos das estratégias de padronização e de variação visual em capas de coleções. Por exemplo, na Rubáiyát (figura 10), a borda se repete, mas são trocadas as cores utilizadas no título e a vinheta; já na Série Obras Educativas (figura 9), mantém-se a mesma estrutura, alterando-se as cores e o lettering do título.

Em relação ao uso de recursos gráficos, identificou-se, em alguns casos, que capas passaram a ser compostas com tipos móveis, eventualmente substituindo letras antes desenhadas à mão. Identificou-se também o uso predominante de três cores na impressão das capas, sempre sólidas.

O exame dos exemplares mostrou que em apenas duas das coleções foi dado crédito ao capista, no caso, Tomás Santa Rosa, responsável pelo projeto de capa das coleções Documentos Brasileiros e Rubáiyát. Pesquisa documental realizada em periódicos da época e documentos da editora custodiados pela Biblioteca Nacional permitiu, contudo, atribuir a Santa Rosa projetos de capas de outras três coleções - Alfredo Pujol, Obras Completas de Humberto de Campos e Série Obras Educativas. A análise comparativa da linguagem gráfica permitiu atribuir a Santa Rosa também o padrão definido para as capas da coleção Pensamento Cristão. Com isso, permanecem anônimos apenas os projetos de capa das duas primeiras coleções da José Olympio (Problemas Políticos Contemporâneos e Menina e Moça).

A pesquisa e a análise realizadas sistematizaram e ampliaram o conhecimento sobre as coleções editadas pela José Olympio nos anos de 1930, tornando mais completo o entendimento sobre o conjunto de publicações e a linguagem gráfica das capas dos livros da editora no período.

A descoberta e a atribuição a Santa Rosa de projetos antes desconhecidas como sendo de sua autoria, por sua vez, ampliaram o repertório de capas do artista gráfico, revelando parte significativa de sua obra, olvidada por outras análises.

\section{Referências}

\section{Fontes primárias}

Bibliografia. Gazeta de Notícias, 9 fev. 1936, p. 10.

Coleção Alfredo Pujol. Diário de Notícias, 22 mar. 1936, p. 19.

Catálogos da Livraria José Olympio Editora: novembro 1936; abril 1937; agosto 1938; março 1944; 1946; 1949.

Livros Novos. O Cruzeiro, $1^{\circ}$ nov. 1941, p. 16.

Movimento Literário. Carioca, 31 ago. 1940, p. 9.

Registros Bibliográficos. Diário de Notícias, 9 fev. 1936, p. 15.

Registro Literário. A Federação, RS, 16 jun. 1936, p. 3.

Santa Rosa. Recibos 1934-1954. Coleção José Olympio, Biblioteca Nacional.

\section{Bibliografia}

Bueno, L. (2015). Capas de Santa Rosa. Cotia/São Paulo: Ateliê Editorial/Edições Sesc.

Cunha Lima, E. L. \& Ferreira, M. C. (2005). Santa Rosa: Um Designer a Serviço da Literatura. Em R. Cardoso, O Design Brasileiro antes do Design (pp. 197-232). São Paulo: CosacNaify. 
Fontana, C. F. \& Farias, P. L., | A linguagem gráfica das capas de coleções da Livraria José Olympio Editora no decênio de 1930: uma análise baseada em princípios do design da informação

Farias, P. L. (2016). Estudos sobre Tipografia: Letras, Memória Gráfica e Paisagens Tipográficas. Tese (Livre-docência). Brasil: USP.

Fontana, C. F. (2018). Standards and Variations: Livraria José Olympio's Book Covers in the 1930s and the 1940s. Em Oriol Moret, Back to the Future. The Future in the Past (pp. 798803). Barcelona: Universitat Barcelona.

Fontana, C. F. (2010). O Trabalho de Poty Lazzarotto como Ilustrador. Dissertação (Mestrado). Brasil: USP.

Hallewell, L. (2012). O Livro no Brasil: Sua História. São Paulo: Edusp.

Nogueira, J. C. G. (2009). Letra e Imagem: A Tipografia nas Capas de Livros Desenhadas por Eugênio Hirsch. Dissertação (Mestrado). Brasil: Unicamp.

Pereira, José Mario (2008). José Olympio, o Editor e sua Casa. Rio de Janeiro: Sextante

Sorá, Gustavo (2010). Brasilianas: José Olympio e a Gênese do Mercado Editorial Brasileiro. São Paulo: Edusp.

Twyman, M. L. (1979). A Schema for the Study of Graphic Language. Em P. A. Kolers, M. E. Wrolstad \& H. Bouma. Processing of Visible Language, vol. 1 (pp. 117-150). Nova York: Plenum Press.

\section{Sobre as autoras}

Carla Fernanda Fontana, Mestre, Doutoranda, USP, Brasil <carlaff@usp.br>

Priscila Lena Farias, Doutora, Professora Associada, USP, Brasil <prifarias@usp.br> 